\title{
Produção de concretos autoadensáveis com alto teor de ar incorporado e propriedades mecânicas para fins estruturais
}

\author{
Production of self-compacting concrete with high \\ entrained air content and mechanical properties \\ for structural purposes
}

\footnotetext{
${ }^{1}$ Departamento de Engenharia de Estruturas, Escola de Engenharia de São Carlos, Universidade de São Paulo - Av. Trabalhador Sancarlense, 400, Centro, CEP 13566-590, São Carlos, SP, Brasil.

e-mail: fmellinmf@gmail.com, alcastro@sc.usp.br
}

\begin{abstract}
RESUMO
O uso de concreto autoadensável já é bastante difundido na construção civil, sendo utilizado principalmente em elementos esbeltos e/ou com altas taxas de armadura. Ainda assim, os efeitos combinados de autoadensabilidade com determinadas estratégias modificadoras das propriedades dos concretos são pouco conhecidos. Esse é o caso observado com o aditivo incorporador de ar. Dessa forma, o presente trabalho busca avaliar a influência da incorporação de ar no comportamento de concretos autoadensáveis mantendo propriedades mecânicas adequadas para uso estrutural. Algumas premissas de interesse foram definidas com base na utilização do material para a execução de paredes de concreto moldadas no local. Assim, foram produzidos dois traços de concreto autoadensável, sem incorporação de ar, com classes de resistência C25 e C40 e, a partir de cada um deles, foram produzidos outros dois traços modificados com aditivo incorporador de ar, variando o teor de ar incorporado, em um total de seis misturas cujas propriedades foram avaliadas tanto no estado fresco quanto no estado endurecido. Os resultados obtidos foram muito satisfatórios, considerando que dois dos traços de concreto autoadensável com incorporação de ar apresentaram propriedades mecânicas adequadas para utilização com função estrutural, apesar do alto teor de ar incorporado.
\end{abstract}

Palavras-chave: Concreto autoadensável. Aditivo incorporador de ar. Autoadensabilidade. Resistência à compressão.

\begin{abstract}
The use of self-compacting concrete is already widespread in civil construction, being used mainly in slender elements and/or with high reinforcement rates. Even so, the combined effects of self-compactability with some strategies for modifying the properties of the concrete are little known. This is the case with the air entraining admixture. Thus, the present paper seeks to evaluate the influence of air entrainment in the behavior of self-compacting concrete maintaining properties suitable for structural purposes. Some premises of interest were defined based on the use of the material for the construction of concrete walls cast in place. For this, two self-compacting concrete mixtures were produced without air entraining and strength classes of $\mathrm{C} 25$ and C40 and, from each of them, two other mixtures modified with air entraining admixture were produced, varying the entrained air content, in a total of six mixtures whose properties were evaluated in both fresh and hardened states. The results obtained were very satisfactory, considering that two of the self-compacting concrete mixtures with air entraining presented mechanical properties suitable for use with structural function, despite the high content of entrained air.
\end{abstract}

Keywords: Self-compacting concrete. Air-entraining admixture. Self-compactability. Compressive strength.

\section{INTRODUÇÃO}

O cenário de euforia na construção civil brasileira em meados de 2010 se mostrou propício para a consagra- 
ção do sistema construtivo de paredes de concreto moldadas no local, em função de sua grande velocidade de execução. O sistema consiste na moldagem de paredes e lajes maciças de concreto armado com telas metálicas centralizadas [1], sendo que as paredes apresentam característica autoportante, ou seja, são responsáveis por suportar as cargas atuantes na estrutura [2].

Os requisitos e procedimentos para o dimensionamento das paredes de concreto moldadas no local são contemplados na NBR 16055:2012 [2]. Dentre as abordagens consideradas nessa norma, ressalta-se a recomendação do uso de concreto autoadensável para sua execução.

De acordo com a NBR 15823-1:2017 [3], o concreto autoadensável (CAA) é definido como o "concreto capaz de fluir, autoadensar pelo seu peso próprio, preencher a fôrma e passar por embutidos (armaduras, dutos e insertos), enquanto mantém sua homogeneidade (ausência de segregação) nas etapas de mistura, transporte, lançamento e acabamento" [3]. Desde seu desenvolvimento, a tecnologia do CAA vem sendo mais claramente aproveitada pela indústria do concreto pré-moldado, já que é possível a concretagem de elementos com altas taxas de armadura, diminuição da mão de obra na operação de moldagem e, ainda, uma redução do ruído proveniente de vibradores e fôrmas vibratórias utilizados em concretos convencionais [4].

Em se tratando do aumento da trabalhabilidade em concretos, além da adição de aditivos plastificantes e/ou superplastificantes, a utilização de aditivo incorporador de ar é outra estratégia que pode ser adotada. Esses aditivos apresentam estrutura química típica que consiste em cadeia hidrocarbônica apolar com um grupo polar aniônico em sua extremidade, o que faz com que vazios de ar sejam incorporados e estabilizados quando da sua adição ao concreto [5]. No entanto, alcançar as características adequadas dos vazios de ar incorporado no CAA não é uma tarefa fácil, uma vez que bolhas de ar no concreto fresco são inerentemente instáveis. As bolhas de ar podem se mover mais livremente no concreto altamente fluido, havendo um aumento na ocorrência de coalescência e ruptura das bolhas de ar. Até certo ponto, uma mistura de CAA com viscosidade alta, geralmente acompanhada de um menor espalhamento, impede que as bolhas de ar se rompam ou coalesçam, criando um "efeito de amortecimento" para que as mesmas absorvam choques causados por qualquer distúrbio, como a mistura [6].

A distribuição do tamanho das bolhas de ar incorporado tem se mostrado essencial para a fluidez do concreto, de maneira que pequenas bolhas de ar melhoraram a autoadensabilidade do concreto fresco, enquanto grandes bolhas de ar incorporado se mostraram instáveis, escapando facilmente da mistura e, assim, reduzindo a estabilidade volumétrica do ar incorporado. Além disso, Puthipad, Ouchi e Attachaiyawuth [7] verificaram que há a possibilidade de pequenas bolhas de ar incorporado se coalescerem com o tempo, formando bolhas de ar grandes e instáveis. De acordo com os resultados do estudo desenvolvido pelos autores, a seleção cuidadosa do aditivo incorporador de ar e o procedimento de mistura podem reduzir o grau de coalescência das pequenas bolhas de ar no CAA.

A fim de aprimorar as características de autoadensabilidade do CAA por meio da incorporação de ar à mistura, ATTACHAIYAWUTH et al. [8] desenvolveram um método de mistura (water-dividing mixing method) em que dosagens excessivas de aditivo incorporador de ar resultaram em altas proporções de bolhas de ar de menor dimensão e, assim, a maior área superficial total das pequenas bolhas de ar incorporado reduziu o atrito interno das partículas de agregados durante o escoamento, aumentando a autoadensabilidade das misturas no estado fresco. Os autores nomearam este material como concreto autoadensável com ar aprimorado (air-enhanced self-compacting concrete ou air-SCC).

Dada a complexidade dos aditivos químicos disponíveis, é impossível generalizar os efeitos de suas interações sobre a incorporação de ar no concreto. LAZNIEWSKA-PIEKARCZYK [9] estudou o efeito individual e conjunto de diferentes aditivos químicos - superplastificante, incorporador de ar, modificador de viscosidade e antiespumante - sobre o teor de ar (porosidade e distribuição do tamanho dos poros) e a trabalhabilidade do CAA de alto desempenho, demonstrando que aditivos de diferentes origens nem sempre não podem ser usados de forma intercambiável, mesmo que sua composição química pareça semelhante. Enquanto a maioria dos estudos sobre os efeitos do ar incorporado na autoadensabilidade do concreto fresco não incluem nenhuma adição mineral, PUTHIPAD et al. [10] investigaram o efeito combinado de rolamento de esferas de cinza volante e das bolhas de ar incorporado, e mostraram que em conjunto a adição de cinza volante e aditivo incorporador de ar podem melhorar as características de autoadensabilidade do concreto. No entanto, a presença de cinza volante na mistura reduziu a estabilidade volumétrica do ar incorporado, causada pelo maior teor de grandes bolhas de ar produzidas e pela coalescência de pequenas bolhas de ar. Ainda, os autores verificaram que a estabilidade das bolhas de ar incorporado foi reduzida à medida que a proporção de cinza volante aumentava.

A melhora da trabalhabilidade nas misturas de concreto produzidas com aditivo incorporador de ar acontece como um efeito colateral causado pelo ar incorporado, associada a uma redução da massa específica 
do concreto e, consequentemente, redução do peso próprio da estrutura que permite que sejam consideradas cargas mais brandas no dimensionamento dos elementos estruturais. Porém, aliado a essas vantagens, as misturas de concreto com ar incorporado em determinadas quantidades sofrem perda de resistência mecânica quando do estado endurecido [5]. Além disso, a garantia de um sistema de bolhas de ar incorporado adequado e estável no CAA é essencial para a durabilidade do material no estado endurecido, particularmente quanto à resistência ao gelo-degelo [11]. Portanto, é necessário que se faça uma análise dos efeitos negativos frente às vantagens obtidas em decorrência da incorporação de ar para que os resultados práticos na construção se enquadrem na regulamentação brasileira.

Neste contexto, o presente trabalho busca avaliar a influência da incorporação de ar no comportamento de concretos autoadensáveis mantendo propriedades adequadas para uso estrutural. Como houve a preocupação de se produzir concretos com características adequadas ao uso em paredes de concreto moldadas no local, conforme observado em FERREIRA [12], os requisitos de autoadensabilidade e resistência à compressão dos concretos produzidos foram definidos com base na NBR 15823-1:2017 [3] e na NBR 16055:2012 [2] de maneira a atender às particularidades de projeto e execução deste sistema construtivo.

\section{MATERIAIS E MÉTODOS}

\subsection{Materiais utilizados}

Em termos de composição, o CAA é um concreto que apresenta os mesmos materiais de um concreto convencional (agregado miúdo, agregado graúdo, cimento Portland e água), com algumas mudanças nas características de alguns componentes, acrescido de aditivos superplastificantes e/ou aditivos modificadores de viscosidade, associados com a incorporação de adições minerais de partículas finas [5, 13].

GOMES e BARROS [13] afirmam ainda que em razão da grande diversidade de aditivos químicos e adições minerais disponíveis no mercado, e às várias combinações que podem ser utilizadas na obtenção das misturas de CAA, a etapa de seleção dos materiais constituintes para a produção deste concreto é a mais trabalhosa no seu estudo de dosagem. Assim, os materiais escolhidos para compor os traços de CAA produzidos e avaliados são:

- cimento Portland composto com escória, com resistência à compressão mínima aos 28 dias de idade de $32 \mathrm{MPa}$ (CPII E 32) e massa específica de $2,89 \mathrm{~kg} / \mathrm{dm}^{3}$;

- duas areias naturais, de origem quartzosa, classificadas como areia fina e areia média, com massa específica de $2,57 \mathrm{~kg} / \mathrm{dm}^{3}$ e $2,58 \mathrm{~kg} / \mathrm{dm}^{3}$, módulo de finura de 1,20 e 2,40, e dimensão máxima característica de $0,6 \mathrm{~mm}$ e $2,36 \mathrm{~mm}$, respectivamente;

- uma brita de origem basáltica, classificada comercialmente como brita 0 , com massa específica de $2,83 \mathrm{~kg} / \mathrm{dm}^{3}$ e dimensão máxima característica de $9,5 \mathrm{~mm}$;

- $\quad$ sílica ativa derivada do processo de produção do silício metálico ou ferro silício, com massa específica de $2,18 \mathrm{~kg} / \mathrm{dm}^{3}$;

- fíler calcário, com massa específica de $2,63 \mathrm{~kg} / \mathrm{dm}^{3}$;

- aditivo superplastificante à base de policarboxilato;

- aditivo incorporador de ar;

- água proveniente da rede de abastecimento local.

\subsection{Produção do concreto autoadensável}

Seguindo a metodologia de dosagem proposta por GOMES [14], foram produzidos inicialmente dois traços de concreto autoadensável sem aditivo incorporador de ar. Estes dois traços de referência, denominados T1 e $\mathrm{T} 2$, foram estabelecidos visando resistências características à compressão $\left(\mathrm{f}_{\mathrm{ck}}\right)$ de 25 e $40 \mathrm{MPa}$, respectivamente. Outros quatro traços foram produzidos a partir dos traços de referência com a adição de aditivo incorporador de ar, identificados por T1_1, T1_2, T2_1 e T2_2, variando-se o teor de ar incorporado à mistura. Detalhes do estudo de dosagem dos concretos autoadensáveis estão disponíveis em FERREIRA [12].

Em se tratando do procedimento de mistura dos concretos, foi utilizada uma betoneira de eixo vertical, conforme a seguinte sequência: inicialmente, os agregados graúdos e miúdos, e cerca de 50\% da água total, foram misturados durante 1 minuto; na sequência, foram adicionados os materiais finos (cimento, fíler calcário e sílica ativa, quando considerada na mistura) e o restante da água, misturando por mais 5 minutos; então, $\mathrm{o}$ aditivo superplastificante foi adicionado e mistura realizada por mais 5 minutos. 
Uma etapa extra foi considerada na produção dos concretos autoadensáveis com incorporação de ar. Após o fim da mistura do concreto, o aditivo incorporador de ar foi adicionado, sendo feitas sucessivas determinações da massa específica do concreto e, consequentemente, do teor de ar ao longo do tempo de mistura para definir o momento de parada. Isso foi feito pois a incorporação de ar se mostrou difícil de controlar, sendo necessário um critério de parada mais rigoroso do que simplesmente um tempo pré-estabelecido. Assim, o critério de parada (fim) da mistura nos traços modificados ficou dependente da massa específica relacionada aos teores de ar incorporado de 9\% (traços T1_1 e T2_1) e 15\% (T1_2 e T2_2), determinados conforme a NBR 9833:2008 [15].

\subsection{Avaliação das propriedades dos concretos no estado fresco}

Considerando a aplicação dos concretos autoadensáveis na execução de paredes de concreto moldadas no local, foram definidas as propriedades de autoadensabilidade das misturas de referência a partir da classificação apresentada na NBR 15823-1:2017 [3] para os diferentes ensaios de caracterização. Os limites estabelecidos no estudo são apresentados na Tabela 1, bem como o método de ensaio empregado.

Tabela 1: Propriedades analisadas para os concretos autoadensáveis no estado fresco.

\begin{tabular}{c|c|c|c}
\hline PROPRIEDADES & CLASSES & LIMITES & MÉTODOS DE ENSAIO \\
\hline Espalhamento & SF 3 & $760 \mathrm{a} 850 \mathrm{~mm}$ & NBR 15823-2:2017 [16] \\
\hline $\mathrm{T}_{500}$ & $V S 1$ & $\leq 2 \mathrm{~s}$ & NBR 15823-2:2017 [16] \\
\hline IEV & IEV 1 & Estável & NBR 15823-2:2017 [16] \\
\hline Anel J & $P J 1$ & 0 a $25 \mathrm{~mm}$ & NBR 15823-3:2017 [17] \\
\hline Caixa L & $P L 2$ & $\begin{array}{c}\geq 0,80, \\
\text { com três barras de aço }\end{array}$ & NBR 15823-4:2017 [18] \\
\hline Funil V & $V F 1$ & $<9 \mathrm{~s}$ & NBR 15823-5:2017 [19] \\
\hline Coluna de segregação & SR 2 & $\leq 15$ & NBR 15823-6:2017 [20] \\
\hline
\end{tabular}

Além das propriedades de autoadensabilidade, no estado fresco, foram determinadas a massa específica e do teor de ar incorporado dos concretos, a partir do método gravimétrico, conforme NBR 9833:2008 [15]. Como a relação água/cimento e o teor de aditivo superplastificante foram mantidos constantes quando da produção dos concretos com aditivo incorporador de ar, foi possível fazer uma análise comparativa entre os comportamentos dos concretos produzidos, a fim de verificar a influência da presença do aditivo incorporador de ar sobre as propriedades dos materiais no estado fresco.

\subsection{Avaliação das propriedades dos concretos no estado endurecido}

Em relação ao concreto no estado endurecido, a influência do aditivo incorporador de ar sobre as propriedades dos concretos autoadensáveis foi analisada considerando os seguintes parâmetros: resistência à compressão [21]; resistência à tração na flexão [22] e por compressão diametral [23]; módulo de elasticidade dinâmico [24]; e velocidade de pulso ultrassônico [25]. As referidas propriedades foram obtidas ao longo do tempo, nas idades de $12,15,18,21$ e 24 horas, 7 e 28 dias.

Para realização dos ensaios no estado endurecido, foram produzidos corpos de prova em duas concepções: cilíndricos, com $100 \mathrm{~mm}$ de diâmetro x $200 \mathrm{~mm}$ de altura; e prismáticos, de $150 \mathrm{~mm}$ x $150 \mathrm{~mm}$ x $500 \mathrm{~mm}$. Para os ensaios de resistências à compressão e à tração por compressão diametral foram ensaiados 3 corpos de prova em cada idade, exceto para obtenção da resistência à compressão aos 28 dias, onde utilizou-se 5 exemplares. Em relação aos prismas, foram produzidos 3 corpos de prova para cada traço, sendo utilizados os mesmos exemplares em todas as idades nos ensaios não destrutivos que, por fim, foram rompidos aos 28 dias no ensaio de resistência à tração na flexão. 


\section{RESULTADOS}

\subsection{Dosagem dos concretos autoadensáveis}

Conforme o estudo de dosagem dos concretos autoadensáveis, sem e com a adição de aditivo incorporador de ar [12], o consumo de materiais para cada um dos seis traços produzidos está apresentado na Tabela 2. É importante observar que, nos traços de prefixo T1, optou-se pela não utilização de sílica ativa, já que a resistência à compressão alvo no traço referência não era elevada. Já nos traços de prefixo T2, a sílica foi utilizada no teor de $10 \%$ em adição ao cimento. Outro ponto de interesse é a menor relação água/cimento nos traços T2, a fim de alcançar maiores resistências no concreto endurecido. Sendo assim, para se alcançar as propriedades de autoadensabilidade estabelecidas, a quantidade de superplastificante utilizada foi maior nos traços T2 justamente pela menor quantidade de água na mistura.

Tabela 2: Consumo de materiais, em $\mathrm{kg} / \mathrm{m}^{3}$, para os traços produzidos.

\begin{tabular}{c|c|c|c|c|c|c}
\hline \multirow{2}{*}{ MATERIAIS } & \multicolumn{7}{|c}{ TRAÇO DE CONCRETO } \\
\cline { 2 - 7 } & T1 & T1_1 & T1_2 & T2 & T2_1 & T2_2 \\
\hline Cimento & 380 & 348 & 325 & 377 & 333 & 314 \\
\hline Sílica ativa & --- & --- & --- & 38 & 34 & 32 \\
\hline Fíler calcário & 190 & 174 & 163 & 188 & 166 & 157 \\
\hline Água & 209 & 191 & 179 & 170 & 150 & 142 \\
\hline Superplastificante & 1,519 & 1,391 & 1,299 & 2,976 & 2,629 & 2,479 \\
\hline Incorporador de ar & --- & 0,696 & 0,650 & --- & 0,333 & 0,628 \\
\hline Areia fina & 307 & 281 & 263 & 318 & 281 & 265 \\
\hline Areia média & 461 & 422 & 394 & 476 & 420 & 396 \\
\hline Brita & 902 & 826 & 771 & 932 & 823 & 776 \\
\hline
\end{tabular}

Com relação ao teor de ar incorporado, os valores obtidos são apresentados na Tabela 3. Pode-se observar que os teores de ar incorporado nos concretos T1_1 (5,4\%) e T1_2 (11,7\%) ficaram um pouco abaixo da expectativa inicial de, respectivamente, $9 \%$ e $15 \%$. Isso ocorreu porque houve certa estabilização na incorporação de ar nesses dois traços ao longo do tempo de mistura. Já nos traços T2_1 e T2_2, os respectivos valores de $9 \%$ e $14,1 \%$ de ar incorporado atenderam aos valores estabelecidos inicialmente. No caso dos concretos de referência (T1 e T2), os teores de ar apresentados correspondem ao teor de ar aprisionado durante a mistura.

A partir das determinações do teor de ar incorporado em diferentes betonadas dos concretos autoadensáveis produzidos, observou-se a tendência dos traços modificados a partir do traço de referência C25 incorporarem menos ar que os traços modificados a partir do traço de referência C40, levando-se em conta as variáveis de tempo e quantidade de aditivo. Para se atingir os teores de ar incorporado medidos nos concretos T1_1 e T1_2 foi necessário utilizar uma quantidade de aditivo incorporador de ar maior que nos concretos T2_1 e T2_2 (Tabela 2), bem como foi necessário um maior tempo de mistura destes concretos para se atingir os teores de ar apresentados na Tabela 3. Isso permite entender que as quantidades de água de amassamento e de aditivo superplastificante interferem na incorporação de ar, uma vez que o consumo de cimento é praticamente igual para as duas misturas. Observações semelhantes do mecanismo de incorporação de ar no concreto fresco foram feitas por DU e FOLLIARD [6].

Tabela 3: Massa específica e teor de ar incorporado obtidos em cada traço de concreto.

\begin{tabular}{c|c|c|c|c|c|c}
\hline \multirow{2}{*}{ PROPRIEDADE } & \multicolumn{7}{c}{ TRAÇO DE CONCRETO } \\
\cline { 2 - 7 } & T1 & T1_1 & T1_2 & T2 & T2_1 & T2_2 \\
\hline Teor de ar $(\%)$ & 0,6 & 5,4 & 11,7 & 0,5 & 9,0 & 14,1 \\
\hline Massa específica $\left(\mathrm{kg} / \mathrm{m}^{3}\right)$ & 2375 & 2260 & 2110 & 2435 & 2227 & 2102 \\
\hline
\end{tabular}




\subsection{Avaliação das propriedades de autoadensabilidade dos concretos no estado fresco}

Os resultados dos ensaios para determinação das propriedades de autoadensabilidade dos seis diferentes traços de concreto produzidos, sem e com aditivo incorporados de ar, são apresentados na Tabela 4. Nas Figuras 1 e 2 são apresentadas amostras de todos os concretos produzidos, após o ensaio de espalhamento, a fim de verificar o índice de estabilidade visual.

Tabela 4: Resultados para os ensaios de autoadensabilidade dos concretos no estado fresco.

\begin{tabular}{c|c|c|c|c|c|c}
\hline \multirow{2}{*}{ PROPRIEDADES } & \multicolumn{7}{|c}{ TRAÇO DE CONCRETO } \\
\cline { 2 - 7 } & T1 & T1_1 & T1_2 & T2 & T2_1 & T2_2 \\
\hline Espalhamento (mm) & 775 & 702 & 705 & 760 & 648 & 593 \\
\hline T $_{500}(\mathrm{~s})$ & 1,63 & 0,97 & 0,76 & 1,37 & 1,24 & 1,53 \\
\hline IEV & Estável & Estável & Estável & Estável & Estável & Estável \\
\hline Anel J (cm) & 675 & 645 & 665 & 755 & 535 & 590 \\
\hline Caixa L & 0,85 & 0,70 & 0,80 & 0,94 & 0,90 & 0,80 \\
\hline Funil V (s) & 3,01 & 2,81 & 3,13 & 6,00 & 5,86 & 3,41 \\
\hline Coluna de Segregação $(\%)$ & 2,4 & 5,6 & 7,8 & 9,4 & 10,3 & 4,5 \\
\hline
\end{tabular}
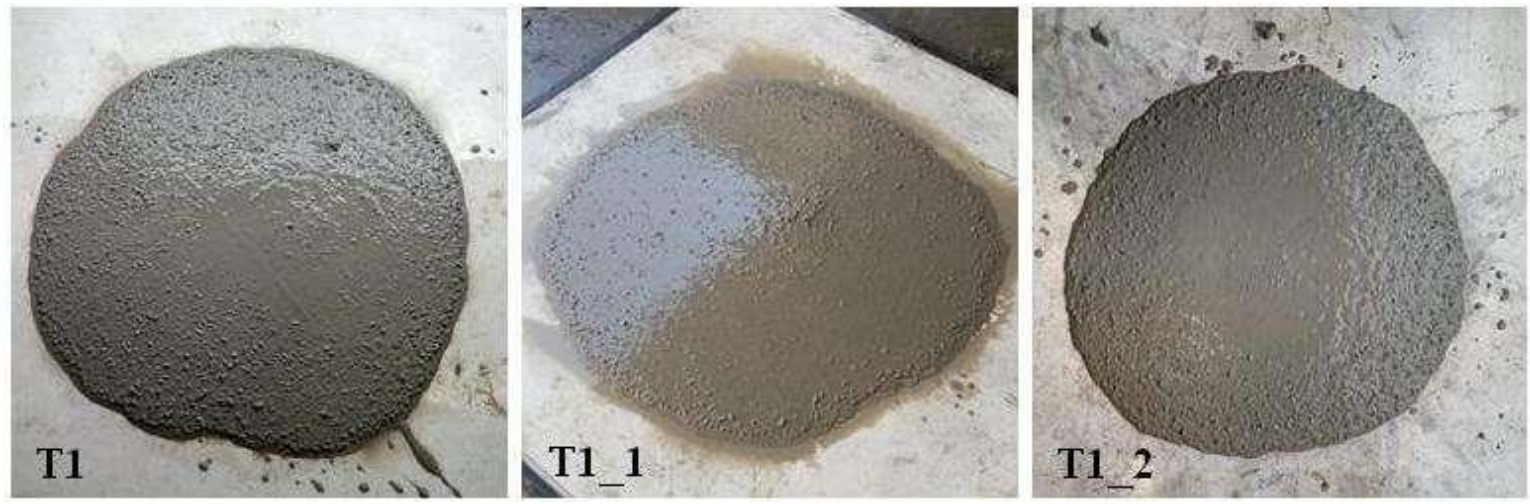

Figura 1: Aparência dos traços T1, T1_1 e T1_2 após o ensaio de espalhamento.
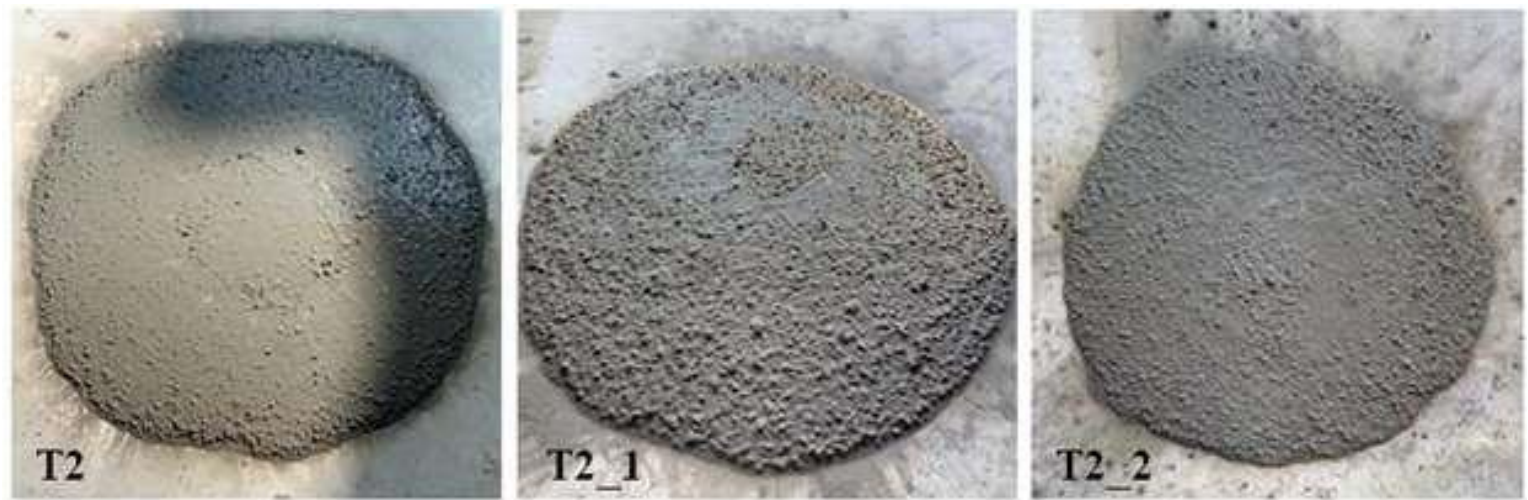

Figura 2: Aparência dos traços T2, T2_1 e T2_2 após o ensaio de espalhamento.

De acordo com os valores apresentados na Tabela 4, verifica-se que os concretos de referência (T1 e T2) apresentaram propriedades de autoadensabilidade de acordo com os limites estabelecidos para todos ensaios (Tabela 1). No entanto, quando da adição do aditivo incorporador de ar, algumas destas propriedades foram prejudicadas, com destaque para o ensaio de espalhamento, onde houve uma redução no valor do espalhamento dos concretos com o uso do aditivo incorporador de ar, enquanto se esperava justamente o contrário 
[26]. Comportamento semelhante foi observado no estudo de LAZNIEWSKA-PIEKARCZYK [9], em que a incorporação de ar reduziu, de maneira significativa, o espalhamento de misturas de CAA de alto desempenho. De qualquer forma, mesmo com a redução do espalhamento, todos os concretos produzidos com ar incorporado apresentam espalhamento que permite sua classificação como autoadensáveis, ou seja, podem ser classificados pelo menos como classe SF1 de acordo com a NBR 15823-1: 2017 [3]. Como mostrado por MONGE e WENDLER [27], essa classe já seria adequada para a construção das paredes de concreto moldadas no local.

De maneira geral, ocorreu a perda das propriedades de autoadensabilidade dos concretos com a incorporação de ar. Como não houve ajuste na quantidade de superplastificante utilizada para a produção dos traços modificados, o maior tempo de mistura destes concretos em comparação com os de referência interferiu na eficiência desses aditivos para manter a trabalhabilidade das misturas ao longo do tempo. A escolha pela manutenção da quantidade de superplastificante (teor de aditivo em relação à massa de cimento) foi feita para manter as características originais dos concretos de referência, para fins comparativos.

\subsection{Avaliação das propriedades dos concretos no estado endurecido}

\subsubsection{Resistência à compressão}

Os valores da resistência média à compressão dos concretos autoadensáveis produzidos sem e com aditivo incorporador de ar, determinados em diferentes idades, são apresentados na Tabela 5. Com exceção da idade de 28 dias, em que foram ensaiados cinco corpos de prova para cada mistura de concreto, os valores correspondem à média de três resultados individuais obtidos em corpos de prova cilíndricos, com 100 mm de diâmetro e $200 \mathrm{~mm}$ de altura. A evolução da resistência à compressão ao longo do tempo para todos os traços desenvolvidos é apresentada nas Figuras 3 e 4, sendo as idades apresentadas em horas. Portanto, 7 dias é referente a 168 horas e 28 dias, a 672 horas. Com base nos resultados apresentados, percebe-se a queda da resistência à compressão decorrente da incorporação de ar ao concreto.

Tabela 5: Resultados de resistência à compressão, em MPa, para os concretos produzidos.

\begin{tabular}{|c|c|c|c|c|c|c|c|c|}
\hline \multirow{2}{*}{\multicolumn{2}{|c|}{$\begin{array}{l}\text { TRAÇO DE } \\
\text { CONCRETO }\end{array}$}} & \multicolumn{7}{|c|}{ IDADE } \\
\hline & & \multirow{2}{*}{$\begin{array}{c}12 \text { horas } \\
1,59\end{array}$} & \multirow{2}{*}{$\begin{array}{c}15 \text { horas } \\
2,65\end{array}$} & \multirow{2}{*}{$\begin{array}{c}18 \text { horas } \\
3,98\end{array}$} & \multirow{2}{*}{$\begin{array}{c}21 \text { horas } \\
6,32\end{array}$} & \multirow{2}{*}{$\begin{array}{c}24 \text { horas } \\
7,55\end{array}$} & \multirow{2}{*}{$\begin{array}{l}7 \text { dias } \\
25,01\end{array}$} & \multirow{2}{*}{$\begin{array}{c}28 \text { dias } \\
43,28\end{array}$} \\
\hline \multirow{3}{*}{$\mathrm{T} 1$} & Média & & & & & & & \\
\hline & DP & 0,10 & 0,10 & 0,13 & 0,13 & 0,27 & 2,91 & 1,37 \\
\hline & $\mathrm{CV}(\%)$ & 6,37 & 3,89 & 3,37 & 2,06 & 3,59 & 11,60 & 3,20 \\
\hline \multirow{3}{*}{$\mathrm{T} 1 \_1$} & Média & 1,82 & 2,42 & 3,32 & 4,27 & 5,27 & 16,89 & 25,47 \\
\hline & DP & 0,60 & 0,62 & 0,33 & 0,35 & 0,33 & 0,69 & 0,32 \\
\hline & $\mathrm{CV}(\%)$ & 33,12 & 25,71 & 10,05 & 8,29 & 6,16 & 4,00 & 1,30 \\
\hline \multirow{3}{*}{$\mathrm{T} 1 \_2$} & Média & 0,66 & 1,03 & 1,64 & 2,29 & 2,72 & 12,24 & 17,88 \\
\hline & DP & 0,13 & 0,37 & 0,31 & 0,44 & 0,20 & 0,91 & 0,97 \\
\hline & $\mathrm{CV}(\%)$ & 20,02 & 36,31 & 19,01 & 19,16 & 7,42 & 7,40 & 5,40 \\
\hline \multirow{3}{*}{$\mathrm{T} 2$} & Média & 1,62 & 3,49 & 6,26 & 9,00 & 11,81 & 42,80 & 62,47 \\
\hline & DP & 0,07 & 0,18 & 0,26 & 0,18 & 0,06 & 1,63 & 2,23 \\
\hline & $\mathrm{CV}(\%)$ & 4,03 & 5,05 & 4,16 & 1,95 & 0,52 & 3,80 & 3,60 \\
\hline \multirow{3}{*}{$\mathrm{T} 2 \_1$} & Média & 2,19 & 3,03 & 4,31 & 6,11 & 6,70 & 25,56 & 43,46 \\
\hline & DP & 0,05 & 0,22 & 0,18 & 0,10 & 0,35 & 0,32 & 0,75 \\
\hline & $\mathrm{CV}(\%)$ & 2,37 & 7,11 & 4,26 & 1,69 & 5,22 & 1,20 & 1,70 \\
\hline \multirow{3}{*}{ T2_2 } & Média & 3,00 & 4,08 & 5,32 & 6,88 & 7,59 & 23,56 & 33,90 \\
\hline & DP & 0,40 & 0,72 & 0,52 & 0,24 & 0,37 & 1,33 & 1,76 \\
\hline & $\mathrm{CV}(\%)$ & 13,34 & 17,67 & 9,80 & 3,45 & 4,92 & 5,60 & 5,20 \\
\hline
\end{tabular}

Nota: $\mathrm{DP}=$ desvio-padrão, em MPa; $\mathrm{CV}=$ coeficiente de variação, em \%. 


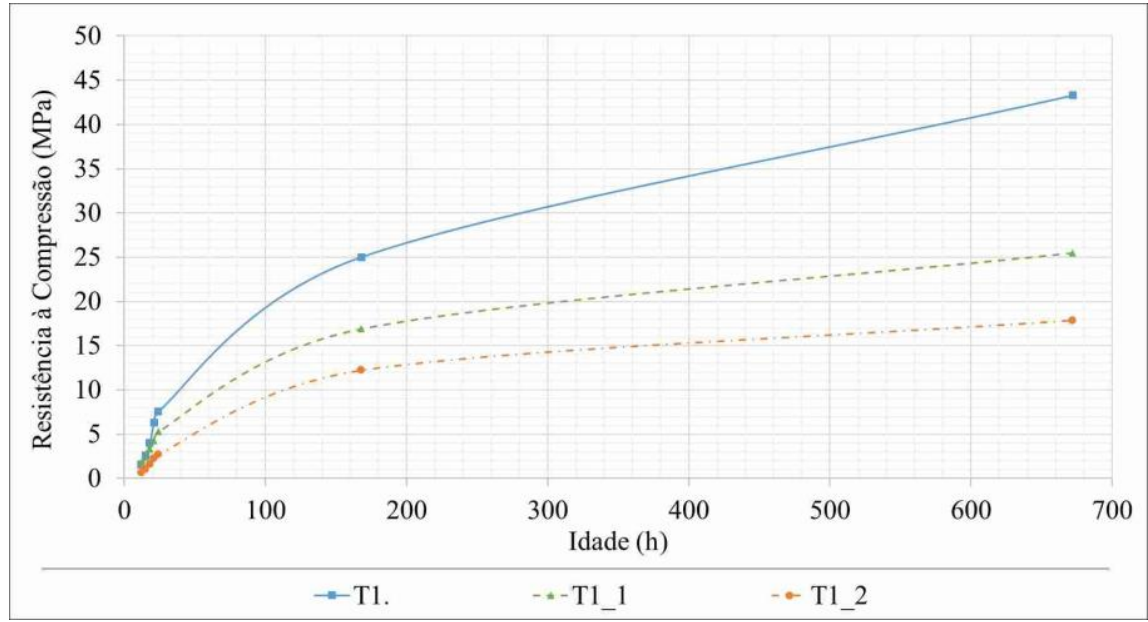

Figura 3: Evolução da resistência à compressão para os traços T1, T1_1 e T1_2.

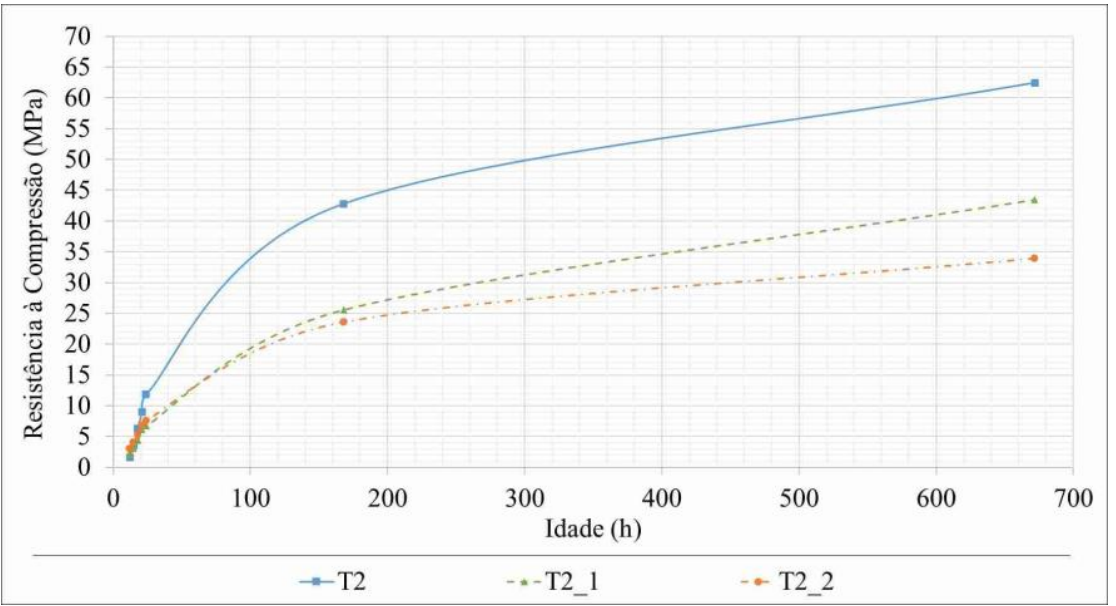

Figura 4: Evolução da resistência à compressão para os traços T2, T2_1 e T2_2.

Segundo a NBR 12655:2015, a resistência de dosagem do concreto deve atender às condições de variabilidade decorrentes da construção [28]. Dessa forma, o valor da resistência média determinada em laboratório deve ser corrigido com um desvio padrão dependente da condição de preparo do concreto para o cálculo da resistência característica à compressão do concreto (Equação 1).

$$
f_{c k j}=f_{c m j}-1,65 \cdot S_{d}
$$

Onde: $f_{c m j}$ é a resistência média do concreto à compressão, prevista para a idade de j dias; $f_{c k j}$ é a resistência característica do concreto à compressão, aos j dias; e $S_{d}$ é o desvio-padrão da dosagem, sendo todos os valores expressos em megapascal $(\mathrm{MPa})$.

Para verificar se os concretos autoadensáveis com aditivo incorporador de ar poderiam ser usados para fins estruturais, foi calculado o valor de $\mathrm{f}_{\text {ck }}$ desses concretos a partir da Equação 1, considerando a idade de 28 dias como referência e um desvio-padrão de $4 \mathrm{MPa}$ especificado para a condição A de preparo do concreto, conforme estabelecido na NBR 12655:2015 [28]. Os resultados do cálculo da resistência característica à compressão dos concretos a partir da resistência à compressão média obtida na idade de 28 dias são apresentados na Tabela 6. Observa-se que os valores da resistência característica à compressão obtidos para os traços de referência T1 e T2 foram superiores aos valores de 25 e $40 \mathrm{MPa}$ estabelecidos inicialmente. O principal ponto positivo observado nos resultados apresentados na Tabela 6 é a obtenção de resistências características à compressão suficientes para caracterização dos traços T2_1 e T2_2 como concretos estruturais, com fck maior que $20 \mathrm{MPa}$, conforme especificado na NBR 8953:2015 [29]. Nesse sentido, estes dois traços se destacaram por apresentarem resistências características à compressão muito próximas de valores usuais de mercado, podendo ser classificados nas classes C35 e C25, respectivamente. Além disso, estes dois traços se destacaram pela redução do consumo de cimento decorrente da incorporação de ar, associada à manutenção da resistência característica à compressão. O efeito positivo da redução do consumo de cimento pela incorpora- 
ção de ar também foi observado por PUTHIPAD, OUCHI e ATTACHAIYAWUTH [7], ATTACHAIYAWUTH et al. [8] e PUTHIPAD et al. [10].

De acordo com KOSMATKA, KERKHOFF e PANARESE [26], a resistência à compressão do concreto tende a ser reduzida de $2 \% \mathrm{a} 6 \%$ a cada aumento de $1 \%$ no teor de ar incorporado à mistura. Isso significa que, para um teor de ar de 5,4\% e 11,7\% incorporado nos concretos T1_1 e T1_2, respectivamente, a redução de resistência máxima observada deveria ser de $28,4 \%$ e 51,5\%. Para os concretos T2_1 e T2_2, com teor de ar incorporado de $9 \%$ e $14,1 \%$, respectivamente, a perda máxima seria de $42,7 \%$ e $58,2 \%$. Neste sentido, na Tabela 6 é apresentada a comparação dos valores de redução da resistência à compressão com a incorporação de ar estimada pelos autores com os valores obtidos no ensaio de resistência à compressão. Com base nas estimativas realizadas, percebe-se que a redução da resistência devido à incorporação de ar se mostrou mais acentuada do que os valores obtidos no ensaio para os traços de prefixo T1, enquanto nos traços de prefixo T2, os valores obtidos estão dentro do limite indicado pelos autores.

Tabela 6: Análises dos resultados de resistência à compressão.

\begin{tabular}{c|c|c|c}
\hline \multirow{2}{*}{$\begin{array}{c}\text { TRAÇO DE } \\
\text { CONCRETO }\end{array}$} & \multirow{2}{*}{$\begin{array}{c}\mathbf{f}_{\text {ck }} \text { CALCULADO } \\
\text { (MPa) [28] }\end{array}$} & \multicolumn{2}{|c}{$\begin{array}{r}\text { REDUÇÃO DA RESISTÊNCIA À COMPRESSÃO AOS } \\
\text { 28 DIAS COM INCORPORAÇÃO DE AR }\end{array}$} \\
\cline { 3 - 4 } & & VALOR ESPERADO (\%) [26] & VALOR OBTIDO (\%) \\
\hline T1 & 36,7 & --- & --- \\
\hline T1_1 & 18,9 & 10,3 a 28,4 & 41,1 \\
\hline T1_2 & 11,3 & 21,0 a 51,5 & 58,7 \\
\hline T2 & 55,9 & --- & --- \\
\hline T2_1 & 36,9 & 16,6 a 42,7 & 30,4 \\
\hline T2_2 & 27,3 & 24,8 a 58,2 & 45,7 \\
\hline
\end{tabular}

\subsubsection{Resistência à tração}

A Tabela 7 apresenta os resultados do ensaio de resistência à tração dos concretos autoadensáveis produzidos, tanto por compressão diametral quanto na flexão, aos 28 dias de idade. Os valores correspondem à média de três resultados individuais obtidos em corpos de prova cilíndricos ou prismáticos, conforme estabelecido para cada ensaio.

Com base nos resultados apresentados na Tabela 7, percebe-se a redução da resistência à tração, tanto por compressão diametral quanto na flexão, com a incorporação de ar às misturas de concreto autoadensável. KOSMATKA, KERKHOFF e PANARESE [26] afirmam que a cada 1\% de aumento no teor de ar incorporado, é observada uma redução de aproximadamente $2 \%$ a $4 \%$ da resistência à tração na flexão. De acordo com os resultados obtidos experimentalmente verifica-se que a queda observada nos valores desta propriedade mecânica se enquadra no intervalo proposto pelos autores para todos os concretos autoadensáveis produzidos com a adição de aditivo incorporador de ar. 
Tabela 7: Resultados de resistência à tração, em MPa, para os concretos produzidos.

\begin{tabular}{|c|c|c|c|}
\hline \multicolumn{2}{|c|}{$\begin{array}{l}\text { TRAÇO DE } \\
\text { CONCRETO }\end{array}$} & $\begin{array}{l}\text { RESISTÊNCIA À TRAÇÃO POR } \\
\text { COMPRESSÃO DIAMETRAL }\end{array}$ & $\begin{array}{c}\text { RESISTÊNCIA À TRAÇÃO NA FLE- } \\
\text { XÃO }\end{array}$ \\
\hline \multirow{3}{*}{$\mathrm{T} 1$} & Média & 3,82 & 5,11 \\
\hline & DP & 0,15 & 0,16 \\
\hline & $\mathrm{CV}(\%)$ & 3,90 & 3,10 \\
\hline \multirow{3}{*}{ T1_1 } & Média & 2,72 & 4,29 \\
\hline & DP & 0,30 & 0,10 \\
\hline & $\mathrm{CV}(\%)$ & 10,80 & 2,30 \\
\hline \multirow{3}{*}{ T1_2 } & Média & 1,63 & 3,23 \\
\hline & DP & 0,13 & 0,30 \\
\hline & $\mathrm{CV}(\%)$ & 7,90 & 9,10 \\
\hline \multirow{3}{*}{$\mathrm{T} 2$} & Média & 4,70 & 7,90 \\
\hline & DP & 0,06 & 0,86 \\
\hline & $\mathrm{CV}(\%)$ & 1,30 & 10,90 \\
\hline \multirow{3}{*}{ T2_1 } & Média & 3,09 & 5,66 \\
\hline & DP & 0,78 & 0,45 \\
\hline & $\mathrm{CV}(\%)$ & 25,30 & 8,00 \\
\hline \multirow{3}{*}{ T2_2 } & Média & 2,30 & 5,03 \\
\hline & DP & 0,07 & 0,28 \\
\hline & $\mathrm{CV}(\%)$ & 3,20 & 5,60 \\
\hline
\end{tabular}

Nota: $\mathrm{DP}=$ desvio-padrão, em MPa; $\mathrm{CV}=$ coeficiente de variação, em \%

\subsubsection{Módulo de elasticidade dinâmico}

Os resultados de módulo de elasticidade dinâmico obtidos a partir do ensaio não destrutivo nos prismas de todos os seis traços de concreto estão mostrados na Tabela 8. Os valores correspondem à média de três resultados individuais obtidos em corpos de prova prismáticos. Além disso, vale ressaltar que o módulo de elasticidade dinâmico apresentado é referente à média dos valores do módulo de vibração longitudinal, conforme sugerido por OTANI e PEREIRA [30]. Com base nos resultados apresentados na Tabela 8, percebe-se a queda do módulo de elasticidade quando da incorporação de ar às misturas de concreto autoadensável.

De acordo com MEHTA e MONTEIRO [5], o módulo de elasticidade dinâmico é dado aproximadamente pelo módulo de deformação tangente inicial e geralmente apresenta valores 20,30 e $40 \%$ superiores ao módulo de elasticidade estático para concretos de alta, média e baixa resistência à compressão, respectivamente. Ainda segundo os autores, concretos de baixa resistência são aqueles com resistência à compressão menor que $20 \mathrm{MPa}$, enquanto os de média resistência se enquadram no intervalo de $20 \mathrm{a} 40 \mathrm{MPa}$, e os de alta resistência acima de $40 \mathrm{MPa}$.

Conforme OTANI e PEREIRA [30] uma das principais equações para a previsão do módulo de elasticidade estático $\left(E_{c}\right)$ a partir do módulo dinâmico $\left(E_{d}\right)$ é dada por POPOVICS [31] e apresentada na Equação 2.

$$
E_{c}=k \cdot E_{d}^{1,4} \cdot \rho^{-1}
$$

Onde $\rho$ é a densidade do concreto no estado endurecido, dada em $\mathrm{kg} / \mathrm{m}^{3}$, e $k$ é uma constante de valor 0,107 quando o módulo é dado em Pa.

Segundo a NBR 6118:2014, para concretos com resistência característica à compressão $\left(\mathrm{f}_{\mathrm{ck}}\right)$ de $20 \mathrm{a}$ $50 \mathrm{MPa}$, o módulo de elasticidade estático $\left(E_{c i}\right)$, considerando o módulo de deformação tangente inicial, pode ser determinado pela Equação 3 [32]. 


$$
E_{c i}=\alpha_{E} \cdot 5600 \cdot \sqrt{f_{c k}}
$$

Onde $E_{c i}$ e $f_{c k}$ são dados em MPa. Como o agregado graúdo utilizado na produção de todos os concretos autoadensáveis estudados é de origem basáltica, o valor de $\alpha_{E}$ deve ser considerado igual a 1,2, conforme estabelecido na NBR 6118:2014 [32].

Tabela 8: Valores de módulo de elasticidade dinâmico, em GPa, dos concretos produzidos.

\begin{tabular}{|c|c|c|c|c|c|c|c|c|}
\hline \multirow{2}{*}{\multicolumn{2}{|c|}{$\begin{array}{l}\text { TRAÇO DE } \\
\text { CONCRETO }\end{array}$}} & \multicolumn{7}{|c|}{ IDADE } \\
\hline & & \multirow{2}{*}{$\begin{array}{c}12 \text { horas } \\
12,97\end{array}$} & \multirow{2}{*}{$\begin{array}{c}\mathbf{1 5} \text { horas } \\
15,11\end{array}$} & \multirow{2}{*}{$\begin{array}{c}18 \text { horas } \\
16,54\end{array}$} & \multirow{2}{*}{$\begin{array}{c}21 \text { horas } \\
17,97\end{array}$} & \multirow{2}{*}{$\begin{array}{c}24 \text { horas } \\
18,92\end{array}$} & \multirow{2}{*}{$\begin{array}{r}\text { dias } \\
32,71\end{array}$} & \multirow{2}{*}{$\begin{array}{c}28 \text { dias } \\
37,18\end{array}$} \\
\hline \multirow{3}{*}{$\mathrm{T} 1$} & Média & & & & & & & \\
\hline & DP & 1,40 & 1,00 & 0,69 & 0,74 & 0,65 & 0,26 & 0,44 \\
\hline & $\mathrm{CV}(\%)$ & 10,78 & 6,62 & 4,19 & 4,10 & 3,45 & 0,8 & 1,2 \\
\hline \multirow{3}{*}{ T1_1 } & Média & 9,21 & 10,74 & 12,63 & 14,34 & 15,56 & 26,71 & 30,48 \\
\hline & DP & 2,39 & 1,72 & 1,07 & 0,64 & 0,34 & 0,35 & 0,64 \\
\hline & $\mathrm{CV}(\%)$ & 25,95 & 15,98 & 8,44 & 4,46 & 2,16 & 1,3 & 2,1 \\
\hline \multirow{3}{*}{ T1_2 } & Média & 3,72 & 5,83 & 7,90 & 9,42 & 10,30 & 21,47 & 24,57 \\
\hline & DP & 1,31 & 1,56 & 0,69 & 0,66 & 0,55 & 0,57 & 0,60 \\
\hline & $\mathrm{CV}(\%)$ & 35,06 & 26,73 & 8,75 & 6,97 & 5,36 & 2,7 & 2,4 \\
\hline \multirow{3}{*}{$\mathrm{T} 2$} & Média & 20,48 & 22,89 & 24,79 & 26,45 & 27,53 & 41,28 & 44,92 \\
\hline & DP & 1,43 & 1,27 & 1,28 & 0,67 & 0,89 & 0,29 & 0,03 \\
\hline & $\mathrm{CV}(\%)$ & 6,99 & 5,53 & 5,15 & 2,52 & 3,23 & 0,70 & 0,10 \\
\hline \multirow{3}{*}{$\mathrm{T} 2 \_1$} & Média & 9,38 & 11,44 & 13,50 & 15,71 & 16,68 & 28,59 & 31,80 \\
\hline & DP & 0,45 & 0,30 & 0,23 & 0,05 & 0,19 & --- & 0,24 \\
\hline & $\mathrm{CV}(\%)$ & 4,80 & 2,64 & 1,70 & 0,34 & 1,15 & --- & 0,80 \\
\hline \multirow{3}{*}{ T2_2 } & Média & 12,72 & 14,37 & 14,93 & 16,33 & 17,05 & 27,80 & 28,93 \\
\hline & DP & 1,57 & 0,72 & 0,81 & 0,50 & 0,62 & 1,76 & 1,10 \\
\hline & $\mathrm{CV}(\%)$ & 12,31 & 5,04 & 5,45 & 3,03 & 3,66 & 6,30 & 3,80 \\
\hline
\end{tabular}

Nota: $\mathrm{DP}=$ desvio-padrão, em MPa; $\mathrm{CV}=$ coeficiente de variação, em \%.

Assim, os valores do módulo de elasticidade estático estimados considerando as correlações entre os módulos dinâmico e estático mencionadas anteriormente são apresentados na Tabela 9. Verifica-se uma proximidade entre os valores obtidos considerando a correlação proposta por MEHTA e MONTEIRO [5] e a Equação 2 de POPOVICS [31]. No entanto, os valores obtidos por meio da Equação 3 constante da NBR 6118:2014 [32] são bem superiores aos obtidos com as correlações anteriores. Esse valor elevado pode ser explicado pelo fato de a referida norma não contemplar os concretos autoadensáveis, que contêm um volume menor de agregado graúdo em sua composição que os concretos convencionais, fazendo com que a equação proposta para obtenção do módulo de elasticidade estático talvez não seja aplicável no concreto em análise. De qualquer forma, entende-se que a maneira adequada de se estabelecer uma correlação direta entre os módulos de elasticidade estático e dinâmico é por meio da realização dos respectivos métodos de ensaio para o mesmo concreto.

KOSMATKA, KERKHOFF e PANARESE [26] indicam uma queda de 0,72 a 1,38 GPa no valor do módulo de elasticidade estático do concreto para cada aumento de $1 \%$ no valor do teor de ar incorporado à mistura. Neste sentido, na Tabela 9 é apresentada a comparação dos valores de redução do módulo de elasticidade estático com a incorporação de ar estimada pelos autores com os valores estimados a partir do $\mathrm{f}_{\mathrm{ck}}$ (Equação 3). Com base nas estimativas realizadas, percebe-se que a redução do módulo devido à incorporação de ar variou com a resistência do concreto, ou seja, a redução estimada pelos autores foi menor do que os valores estimados pela equação para os traços de prefixo $\mathrm{T} 1$, enquanto nos traços de prefixo T2, os valores 
estimados pela equação estão dentro do limite indicado pelos autores.

Tabela 9: Estimativa do módulo de elasticidade estático a partir do módulo de elasticidade dinâmico, considerando diferentes correlações estabelecidas na literatura.

\begin{tabular}{|c|c|c|c|c|c|}
\hline \multirow{2}{*}{$\begin{array}{c}\text { TRAÇO } \\
\text { DE CON- } \\
\text { CON- } \\
\text { CRETO }\end{array}$} & \multicolumn{3}{|c|}{$\begin{array}{l}\text { MÓDULO DE ELASTICIDADE ESTÁ- } \\
\text { TICO (GPa), ESTIMADO }\end{array}$} & \multicolumn{2}{|c|}{$\begin{array}{l}\text { REDUÇÃO DO MÓDULO DE ELASTICIDADE ESTÁ- } \\
\text { TICO COM INCORPORAÇÃO DE AR (GPa) }\end{array}$} \\
\hline & $\begin{array}{c}\text { Mehta e } \\
\text { Monteiro } \\
\text { [5] }\end{array}$ & $\begin{array}{l}\text { Popovics } \\
\text { [31] }\end{array}$ & $\begin{array}{c}\text { NBR } \\
6118: 2014 \\
{[32]}\end{array}$ & VALOR ESPERADO [26] & $\begin{array}{l}\text { VALOR OBTIDO } \\
\text { [32] }\end{array}$ \\
\hline $\mathrm{T} 1$ & 26,0 & 27,5 & 40,7 & --- & --- \\
\hline T1_1 & 18,3 & 22,1 & 29,2 & 3,89 a 7,45 & 11,5 \\
\hline T1_2 & 14,7 & 17,3 & 22,6 & 8,42 a 16,2 & 18,1 \\
\hline $\mathrm{T} 2$ & 35,9 & 34,4 & 50,2 & --- & --- \\
\hline $\mathrm{T} 2 \_1$ & 22,3 & 24,1 & 40,8 & 6,48 a 12,40 & 9,4 \\
\hline T2_2 & 20,3 & 21,8 & 35,1 & 10,20 a 19,50 & 15,1 \\
\hline
\end{tabular}

\subsubsection{Velocidade de pulso ultrassônico}

Outro ensaio realizado nos prismas foi o de ultrassom. Segundo a NBR 8802:2019, esse é um ensaio nãodestrutivo que tem como objetivo determinar a velocidade de propagação de ondas, obtidas por pulsos ultrassônicos, em concreto [25]. De acordo com a ASTM C 597-16, o ensaio permite determinar a uniformidade e a qualidade relativa do concreto com base na velocidade de propagação do som por seu interior [33]. Apesar da grande variedade de fatores que interferem na velocidade de propagação de ondas no concreto, Feldman [34] apresentou uma relação geral entre a qualidade do concreto e a velocidade do pulso ultrassônico, conforme apresentado na Tabela 10.

Tabela 10: Condição geral do concreto em função da velocidade de pulso ultrassônico (adaptado de Feldman [34]).

\begin{tabular}{c|c|c}
\hline \multirow{2}{*}{ CONDIÇÃO GERAL DO CONCRETO } & \multicolumn{2}{|c}{ VELOCIDADE DO PULSO ULTRASSÔNICO } \\
\cline { 2 - 3 } & $\mathbf{f t} / \mathbf{s}$ & $\mathbf{m} / \mathbf{s}$ \\
\hline Excelente & $>15000$ & $>4572$ \\
\hline Boa & 12000 a 15000 & 3658 a 4752 \\
\hline Questionável & 10000 a 12000 & 3048 a 3658 \\
\hline Ruim & 7000 a 10000 & 2134 a 3048 \\
\hline Muito ruim & $<7000$ & $<2134$ \\
\hline
\end{tabular}

Na Tabela 11 são apresentados os valores da velocidade de pulso ultrassônico medidos para os traços de concreto autoadensável produzidos sem e com aditivo incorporador de ar, e correspondem à média de três resultados individuais obtidos em corpos de prova prismáticos. Observa-se que a incorporação de ar nos concretos de referência reduziu a velocidade do pulso ultrassônico, o que significa perda relativa de qualidade do concreto em função da presença das bolhas de ar incorporado por meio da adição do aditivo incorporador de ar. Entretanto, apesar da redução verificada, os valores de velocidade obtidos em todos os seis traços permitem classificar os concretos produzidos como sendo de boa qualidade a partir dos 7 dias de idade. 
Tabela 11: Velocidade de pulso ultrassônico, em m/s, para os concretos produzidos.

\begin{tabular}{|c|c|c|c|c|c|c|c|c|}
\hline \multirow{2}{*}{\multicolumn{2}{|c|}{$\begin{array}{l}\text { TRAÇO DE } \\
\text { CONCRETO }\end{array}$}} & \multicolumn{7}{|c|}{ IDADE } \\
\hline & & \multirow{2}{*}{$\begin{array}{c}12 \text { horas } \\
3090,1\end{array}$} & \multirow{2}{*}{$\frac{15 \text { horas }}{3237,2}$} & \multirow{2}{*}{$\frac{18 \text { horas }}{3338,0}$} & \multirow{2}{*}{$\begin{array}{c}21 \text { horas } \\
3416,6\end{array}$} & \multirow{2}{*}{$\begin{array}{c}24 \text { horas } \\
3478,5\end{array}$} & \multirow{2}{*}{$\begin{array}{l}7 \text { dias } \\
4271,4\end{array}$} & \multirow{2}{*}{$\frac{28 \text { dias }}{4477,3}$} \\
\hline & Média & & & & & & & \\
\hline \multirow[t]{2}{*}{$\mathrm{T} 1$} & DP & 135,8 & 130,8 & 126,5 & 106,4 & 118,8 & 55,3 & 54,3 \\
\hline & $\mathrm{CV}(\%)$ & 4,40 & 4,04 & 3,79 & 3,11 & 3,41 & 1,30 & 1,20 \\
\hline \multirow{3}{*}{ T1_1 } & Média & 2633,9 & 2873,8 & 3124,0 & 3276,3 & 3383,2 & 4093,8 & 4319,4 \\
\hline & DP & 326,6 & 224,1 & 211,6 & 186,5 & 189,5 & 154,2 & 131,3 \\
\hline & CV (\%) & 12,40 & 7,80 & 6,77 & 5,69 & 5,60 & 3,80 & 3,00 \\
\hline \multirow{3}{*}{ T1_2 } & Média & 1723,7 & 2139,3 & 2586,7 & 2715,6 & 2844,5 & 3840,5 & 4068,0 \\
\hline & DP & 283,1 & 284,8 & 241,2 & 185,3 & 196,8 & 149,4 & 152,8 \\
\hline & $\mathrm{CV}(\%)$ & 16,42 & 13,31 & 9,32 & 6,82 & 6,92 & 3,90 & 3,80 \\
\hline \multirow{3}{*}{$\mathrm{T} 2$} & Média & 3586,5 & 3711,5 & 3817,6 & 3926,5 & 3960,4 & 4562,0 & 4711,7 \\
\hline & DP & 114,7 & 97,7 & 88,5 & 70,2 & 65,1 & 37,4 & 35,9 \\
\hline & $\mathrm{CV}(\%)$ & 3,20 & 2,63 & 2,32 & 1,79 & 1,64 & 0,80 & 0,80 \\
\hline \multirow{3}{*}{ T2_1 } & Média & 3006,9 & 3163,2 & 3440,2 & 3506,3 & 3589,5 & 4188,3 & 4476,8 \\
\hline & DP & 263,9 & 207,6 & 255,4 & 189,3 & 190,0 & 128,7 & 139,9 \\
\hline & $\mathrm{CV}(\%)$ & 8,78 & 6,56 & 7,42 & 5,40 & 5,29 & 3,10 & 3,10 \\
\hline \multirow{3}{*}{ T2_2 } & Média & 2922,4 & 3171,7 & 3234,8 & 3357,3 & 3422,0 & 4143,7 & 4274,4 \\
\hline & DP & 265,6 & 148,8 & 132,9 & 138,1 & 139,1 & 135,0 & 142,6 \\
\hline & $\mathrm{CV}(\%)$ & 9,09 & 4,69 & 4,11 & 4,11 & 4,06 & 3,30 & 3,30 \\
\hline
\end{tabular}

Nota: $\mathrm{DP}=$ desvio-padrão, em m/s; CV = coeficiente de variação, em \%.

\subsubsection{Correlação entre as propriedades dos concretos no estado endurecido}

Para cada concreto produzido e estudado no trabalho, foram elaborados gráficos correlacionando as diferentes propriedades do material no estado endurecido, isto é, o módulo de elasticidade dinâmico, a resistência à compressão e a velocidade do pulso ultrassônico em todas as idades de ensaio, conforme apresentado nas Figuras 5 a 10. Os valores apresentados são referentes aos valores médios obtidos em cada um dos ensaios.

Os gráficos apresentados nas Figuras 5 a 10 mostram a tendência de as curvas de velocidade do pulso ultrassônico apresentarem a mesma configuração observada para o módulo de elasticidade dinâmico. Isso ocorre porque, conforme ASTM C 597-16 (ASTM, 2016), a velocidade do pulso ultrassônico é proporcional ao valor do módulo de elasticidade, respeitando a relação apresentada na Equação 4.

$$
V=\sqrt{\frac{E \cdot(1-v)}{\rho \cdot(1+v) \cdot(1-2 v)}}
$$

Onde: $E$ é o módulo de elasticidade dinâmico; $v$ é o coeficiente de Poisson; e $\rho$ é a densidade.

Observa-se também a tendência de estabilização dos valores de velocidade do pulso ultrassônico e dos módulos de elasticidade a partir dos 7 dias de idade. Por outro lado, a resistência à compressão não apresenta essa estabilização, indicando uma tendência de ganho de resistência após os 28 dias de idade.

Comparando a evolução das propriedades dos concretos autoadensáveis, sem e com a adição do aditivo incorporador de ar, no estado endurecido ao longo do tempo, verifica-se que a resistência à compressão e o módulo de elasticidade dinâmico foram mais afetados pela incorporação de ar do que a velocidade do pulso ultrassônico. Isto está relacionado ao aumento da porosidade dos concretos com a incorporação de ar, interferindo diretamente sobre as propriedades mecânicas do material. No entanto, como as bolhas de ar incorporado possuem diâmetro reduzido, mesmo nos concretos com alto teor de ar, sua presença não foi suficiente para interferir na propagação de ondas ultrassônicas no interior do material e, assim, influenciando de uma manei- 
ra menos efetiva nos resultados obtidos a partir do ensaio de ultrassom.

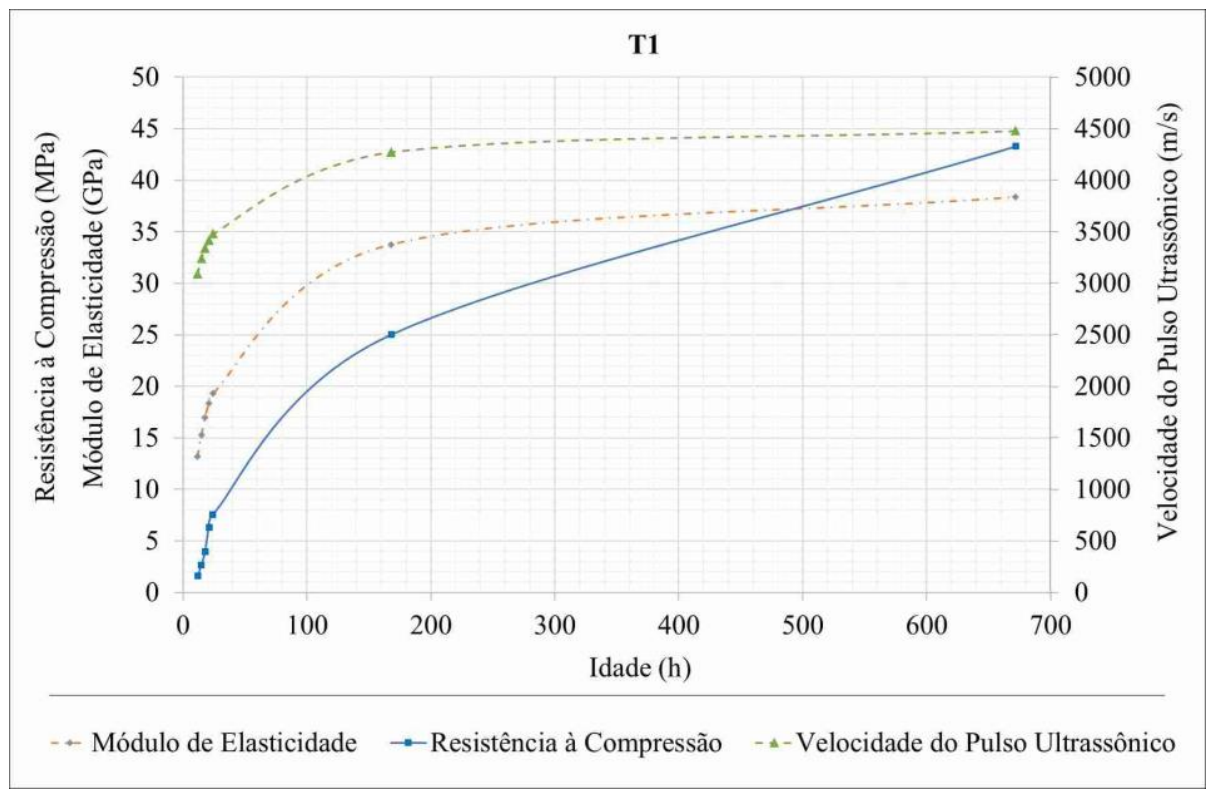

Figura 5: Propriedades do concreto T1, no estado endurecido, ao longo do tempo.

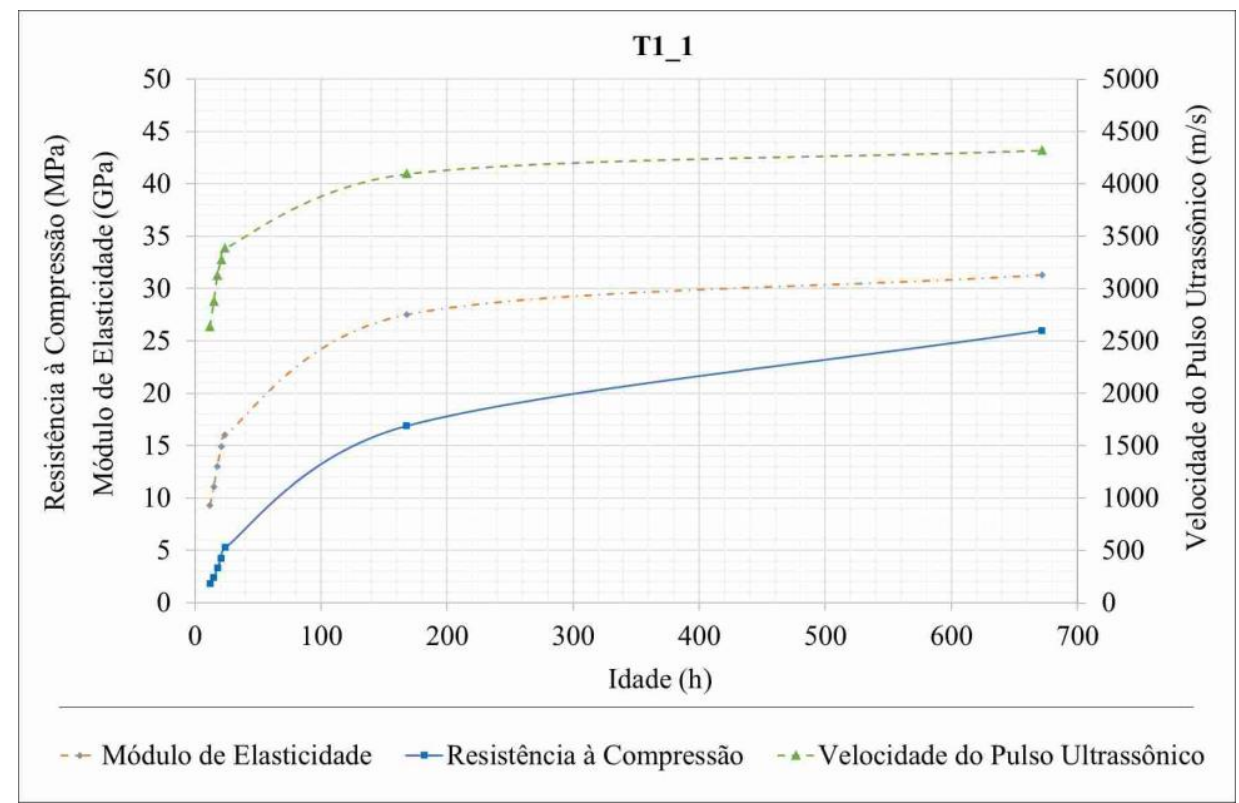

Figura 6: Propriedades do concreto T1_1, no estado endurecido, ao longo do tempo. 


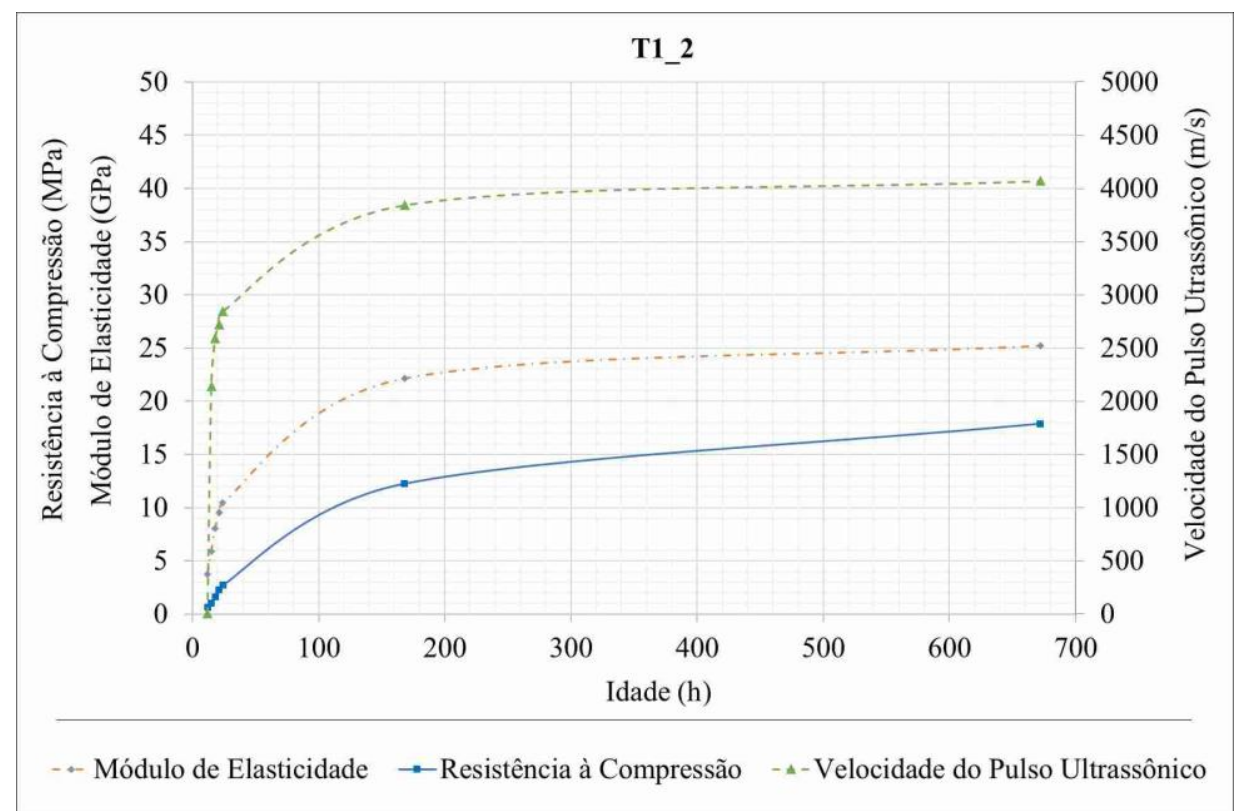

Figura 7: Propriedades do concreto T1_2, no estado endurecido, ao longo do tempo.

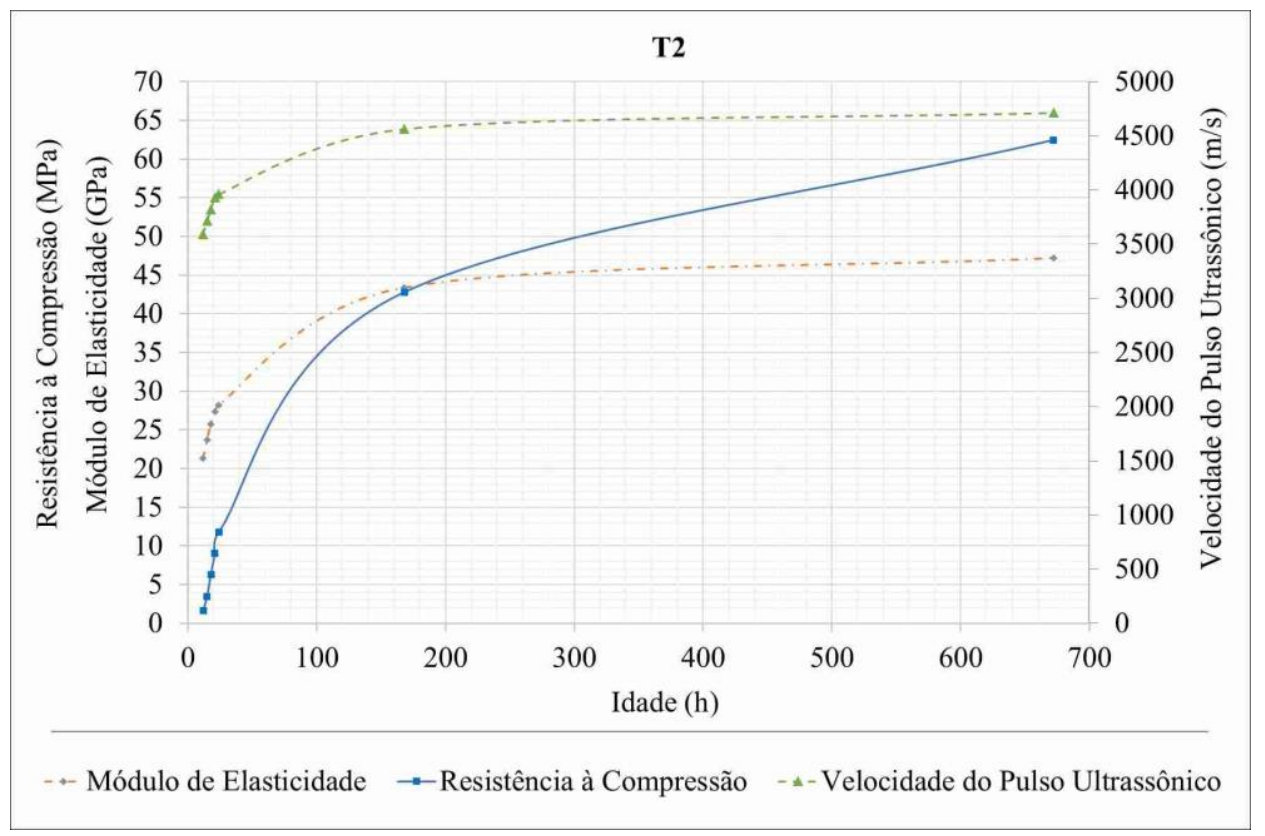

Figura 8: Propriedades do concreto T2, no estado endurecido, ao longo do tempo. 


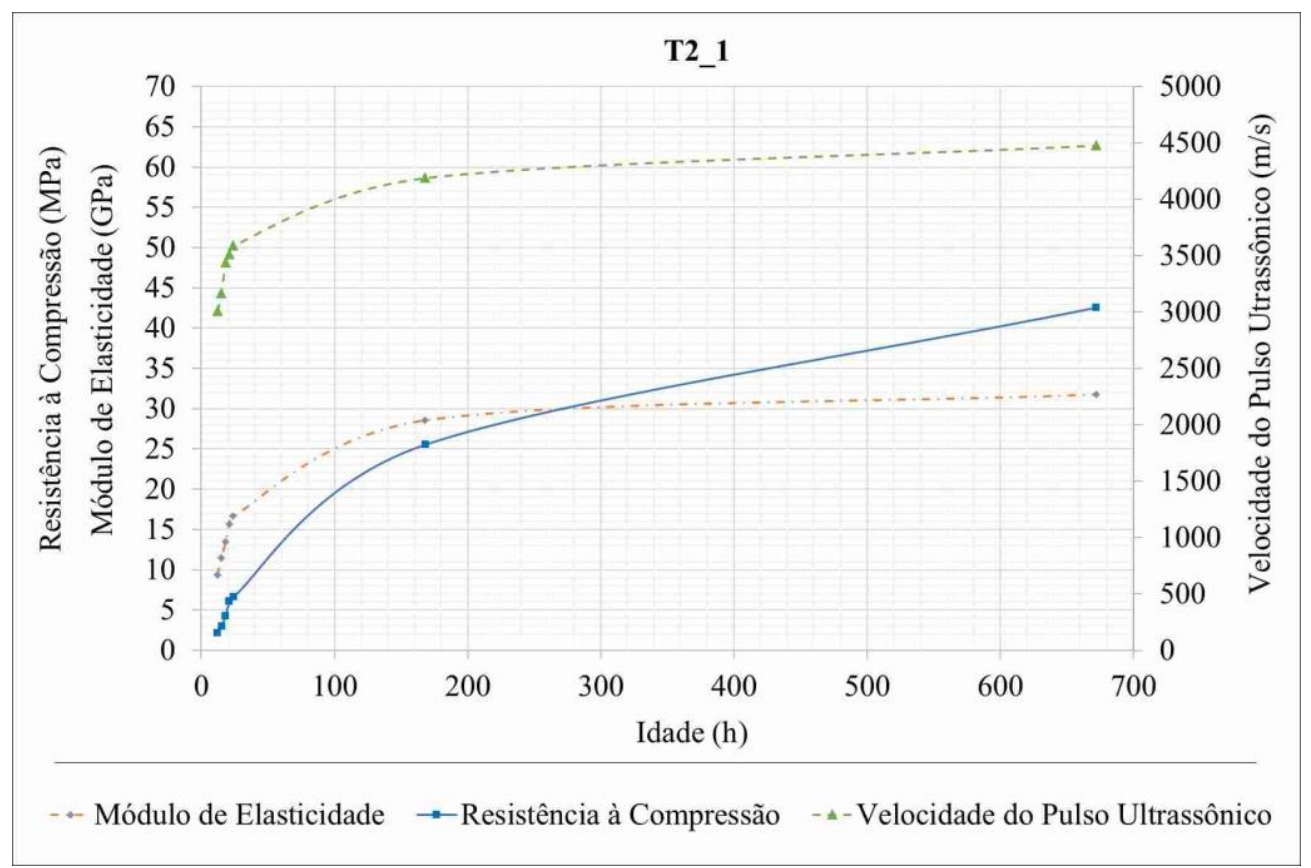

Figura 9: Propriedades do concreto T2_1, no estado endurecido, ao longo do tempo.

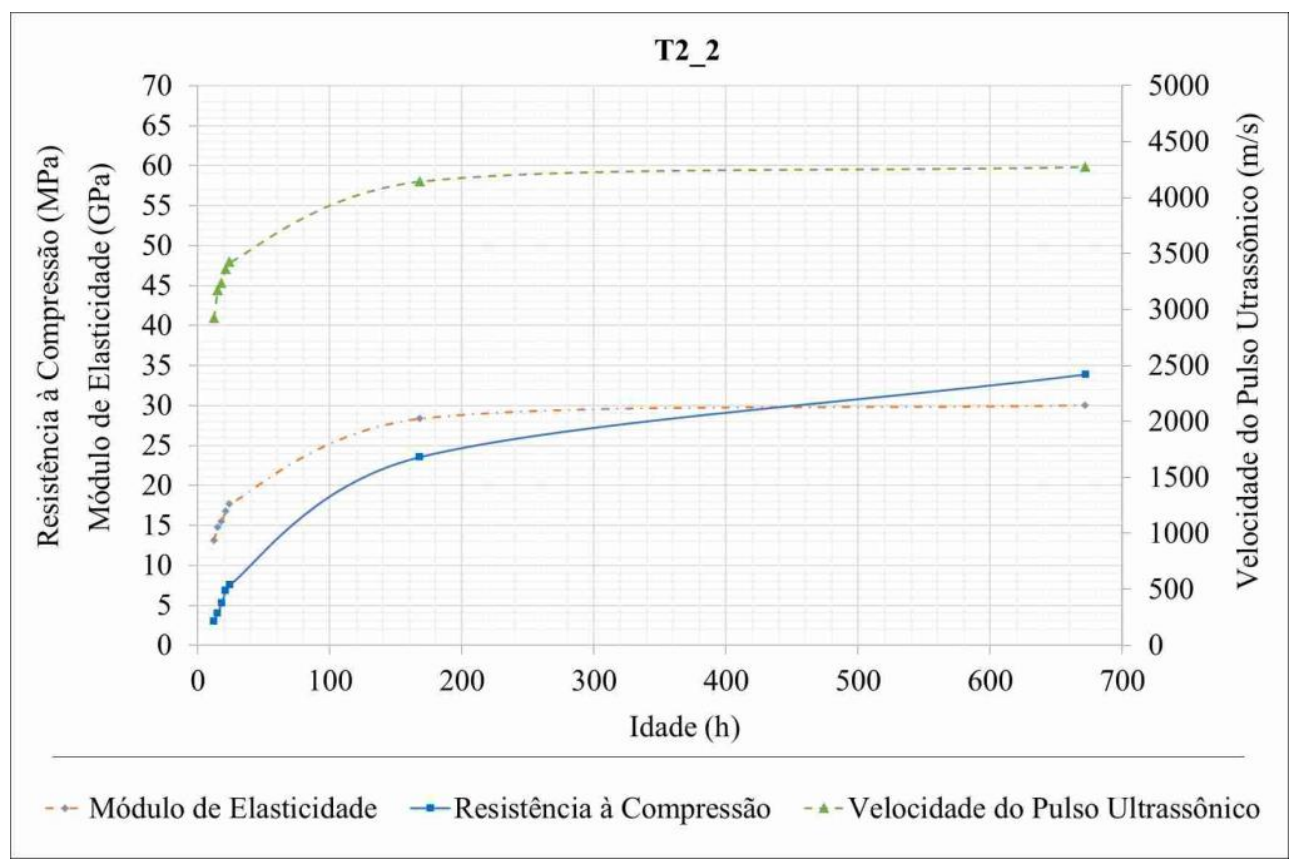

Figura 10: Propriedades do concreto T2_2, no estado endurecido, ao longo do tempo. 


\section{CONCLUSÕES}

Com base nos resultados obtidos experimentalmente, foi possível observar a grande influência exercida pela incorporação de ar sobre o comportamento de concretos autoadensáveis.

No estado fresco, observou-se a perda de algumas características de autoadensabilidade nos concretos com ar incorporado quando em comparação com os concretos de referência, especialmente em termos de espalhamento. Entende-se que esses resultados decorreram da manutenção do teor de aditivo superplastificante utilizado nas misturas de referência, de forma que, com o maior tempo de mistura dos traços modificados, a eficiência do aditivo superplastificante foi comprometida, impossibilitando a manutenção das características de autoadensabilidade inicialmente estabelecidas, considerando a aplicação dos concretos na execução de paredes moldadas no local.

Em relação ao comportamento dos concretos no estado endurecido, houve grande impacto nas propriedades analisadas, principalmente sobre as resistências mecânicas e módulo de elasticidade dinâmico. Ainda assim, dada a elevada resistência à compressão do traço T2, mesmo com a grande perda de resistência devido ao elevado teor de ar incorporado, os traços T2_1 e T2_2 apresentaram resistência suficiente para sua classificação como concretos estruturais. Estes dois traços se destacaram, ainda, pela redução do consumo de cimento decorrente da incorporação de ar, associada à manutenção da resistência característica à compressão muito próxima de valores usuais de mercado. Ressalta-se que, em termos de qualidade do concreto relativa à velocidade do pulso ultrassônico, todos os traços produzidos foram definidos como sendo de boa qualidade.

Ao longo do tempo, a evolução das curvas do módulo de elasticidade dinâmico e velocidade do pulso ultrassônico apresentaram a mesma tendência, indicando uma estabilização a partir dos 7 dias de idade, enquanto a resistência à compressão apresentou tendência de crescimento após a idade de 28 dias. Além disso, verifica-se que a resistência à compressão e o módulo de elasticidade dinâmico foram mais afetados pela incorporação de ar do que a velocidade do pulso ultrassônico.

\section{AGRADECIMENTOS}

Os autores gostariam de agradecer à Coordenação de Aperfeiçoamento de Pessoal de Nível Superior (CAPES) pela bolsa de mestrado financiada, e às empresas GCP Applied Technologies, LafargeHolcim e Elkem Materials South America Ltda. pela doação dos materiais utilizados na pesquisa.

\section{BIBLIOGRAFIA}

[1] SILVA, F.B., "Paredes de concreto armado moldadas in loco". Revista Téchne, v. 167. 2011.

[2] ASSOCIAÇÃO BRASILEIRA DE NORMAS TÉCNICAS, NBR 16055: Parede de concreto moldada no local para a construção de edificações - Requisitos e procedimentos, Rio de Janeiro, 2012.

[3] ASSOCIAÇÃO BRASILEIRA DE NORMAS TÉCNICAS, NBR 15823-1: Concreto autoadensável Parte 1: Classificação, controle e recebimento no estado fresco, Rio de Janeiro, 2017.

[4] EL DEBS, M.K., Concreto pré-moldado: fundamentos e aplicações, 2.ed., São Paulo, Oficina de Textos, 2017.

[5] MEHTA, P.K., MONTEIRO, P.J.M., Concreto: microestrutura, propriedades e materiais, 2.ed., São Paulo, IBRACON, 2014.

[6] DU, L., FOLLIARD, K.J., "Mechanisms of air entrainment in concrete", Cement and Concrete Research, v. 35, pp. 1463-1471, 2005.

[7] PUTHIPAD, N., OUCHI, M., ATTACHAIYAWUTH, A., "Effects of fly ash, mixing procedure and type of air-entraining agent on coalescence of entrained air bubbles in mortar of self-compacting concrete at fresh state", Construction and Building Materials, v.180, pp. 437-444, 2018.

[8] ATTACHAIYAWUTH, A., et al., "Improvement of self-compactability of air-enhanced self-compacting concrete with fine entrained air", Journal of Advanced Concrete Technology, v. 14, n. 3, pp. 55-69, 2016.

[9] LAZNIEWSKA-PIEKARCZYK, B., "The influence of admixtures type on the air-voids parameters of non-air-entrained and air-entrained high performance SCC', Construction and Building Materials, v. 41, pp. 109-124, 2013.

[10] PUTHIPAD, N., et al., "Enhancement in self-compactability and stability in volume of entrained air in self-compacting concrete with high volume fly ash", Construction and Building Materials, v. 128, pp. 349- 
369, 2016.

[11] KHAYAT, K.H., ASSAAD, J., "Air-void stability in self-consolidating concrete", ACI Materials Journal, v. 99, n. 4, pp. 408-416, 2002.

[12] FERREIRA, F.M.M., Influência da incorporação de ar em concreto autoadensável para paredes de concreto moldadas no local, Dissertação de M.Sc., Escola de Engenharia de São Carlos, Universidade de São Paulo, São Carlos, SP, Brasil, 2019.

[13] GOMES, P.C.C., BARROS, A.R., Métodos de dosagem de concreto autoadensável, São Paulo, PINI, 2009.

[14] GOMES, P.C.C., Optimization and characterization of high-strength self-compacting concrete, Tese de D.Sc., Escola Tècnica Superior D'Enginyers de Camins, Universitat Politècnica de Catalunya, Barcelona, Espanha, 2002.

[15] ASSOCIAÇÃO BRASILEIRA DE NORMAS TÉCNICAS, NBR 9833: Concreto fresco - Determinação da massa específica, do rendimento e do teor de ar pelo método gravimétrico, Rio de Janeiro, 2008.

[16] ASSOCIAÇÃO BRASILEIRA DE NORMAS TÉCNICAS, NBR 15823-2: Concreto autoadensável Parte 2: Determinação do espalhamento, do tempo de escoamento e do índice de estabilidade visual - Método do cone de Abrams, Rio de Janeiro, 2017.

[17] ASSOCIAÇÃO BRASILEIRA DE NORMAS TÉCNICAS, NBR 15823-3: Concreto autoadensável Parte 3: Determinação da habilidade passante - Método do anel J, Rio de Janeiro, 2017.

[18] ASSOCIAÇÃO BRASILEIRA DE NORMAS TÉCNICAS, NBR 15823-4: Concreto autoadensável Parte 4: Determinação da habilidade passante - Métodos da caixa L e da caixa U, Rio de Janeiro, 2017.

[19] ASSOCIAÇÃO BRASILEIRA DE NORMAS TÉCNICAS, NBR 15823-5: Concreto autoadensável Parte 5: Determinação da viscosidade - Método do funil V, Rio de Janeiro, 2017.

[20] ASSOCIAÇÃO BRASILEIRA DE NORMAS TÉCNICAS, NBR 15823-6: Concreto autoadensável Parte 6: Determinação da resistência à segregação - Métodos da coluna de segregação e da peneira, Rio de Janeiro, 2017.

[21] ASSOCIAÇÃO BRASILEIRA DE NORMAS TÉCNICAS, NBR 5739: Concreto - Ensaio de compressão de corpos de prova cilíndricos, Rio de Janeiro, 2018.

[22] ASSOCIAÇÃO BRASILEIRA DE NORMAS TÉCNICAS, NBR 12142: Concreto - Determinação da resistência à tração na flexão de corpos de prova prismáticos, Rio de Janeiro, 2010.

[23] ASSOCIAÇÃO BRASILEIRA DE NORMAS TÉCNICAS, NBR 7222: Concreto e argamassa - Determinação da resistência à tração por compressão diametral de corpos de prova cilíndricos, Rio de Janeiro, 2011.

[24] AMERICAN SOCIETY FOR TESTING AND MATERIALS, ASTM E1876: Standard Test Method for Dynamic Young's Modulus, Shear Modulus, and Poisson's Ratio by Impulse Excitation of Vibration, ASTM International, 2015.

[25] ASSOCIAÇÃO BRASILEIRA DE NORMAS TÉCNICAS, NBR 8802: Concreto endurecido - Determinação da velocidade de propagação de onda, Rio de Janeiro, 2019.

[26] KOSMATKA, S.H., KERKHOFF, B., PANARESE, W.C., Design and Control of Concrete Mixtures, EB001, 14.ed., Skokie, Illinois, USA, Portland Cement Association, 2002.

[27] MONGE, R., WENDLER, A., "Paredes de concreto: como ter uma obra sem manifestações patológicas", Concreto \& Construções, v. 90, pp. 38-41, 2018.

[28] ASSOCIAÇÃO BRASILEIRA DE NORMAS TÉCNICAS, NBR 12655: Concreto de cimento Portland - Preparo, controle, recebimento e aceitação - Procedimento, Rio de Janeiro, 2015.

[29] ASSOCIAÇÃO BRASILEIRA DE NORMAS TÉCNICAS, NBR 8953: Concreto para fins estruturais Classificação pela massa especifica, por grupos de resistência e consistência, Rio de Janeiro, 2015.

[30] OTANI, L.B., PEREIRA, A.H.A., "Estimativa do módulo de elasticidade estático de concretos utilizando a Técnica de Excitação por Impulso", Informativo técnico-científico ITC-07/ATCP, 2017.

[31] POPOVICS, S., "Verification of relationships between mechanical properties of concrete like materials", Matériaux et Constructions, v. 8., pp. 183-191, 1975.

[32] ASSOCIAÇÃO BRASILEIRA DE NORMAS TÉCNICAS, NBR 6118: Projeto de estruturas de concreto - Procedimento, Rio de Janeiro, 2014.

[33] AMERICAN SOCIETY FOR TESTING AND MATERIALS, ASTM C597: Standard Test Method for 
Pulse Velocity Through Concrete, ASTM International, 2016.

[34] FELDMAN, R.F., "Non-Destructive Testing of Concrete", CBD-187, National Research Council of Canada, 1977.

\section{ORCID}

Fernando Mellin Moreira Ferreira

https://orcid.org/0000-0003-3523-8900

Alessandra Lorenzetti de Castro

https://orcid.org/0000-0002-7248-7327 